\title{
The Production of 1,8-Cineole, a Potential Biofuel, from an Endophytic Strain of Annulohypoxylon sp. FPYF3050 When Grown on Agricultural Residues
}

\author{
K. Y. Wang1 , G. A. Strobel ${ }^{2 *}$, D.-H. Yan ${ }^{{ }^{*}}$ \\ ${ }^{1}$ The Research Institute of Forest Ecology, Environment and Protection, Chinese Academy of Forestry, Beijing, China \\ ${ }^{2}$ Department of Plant Sciences, Montana State University, Bozeman, MT, USA \\ Email: *yandh@caf.ac.cn, uplgs@montana.edu
}

How to cite this paper: Wang, K.Y., Strobel, G.A. and Yan, D.-H. (2017) The Production of 1,8-Cineole, a Potential Biofuel, from an Endophytic Strain of Annulohypoxylon sp. FPYF3050 When Grown on Agricultural Residues. Journal of Sustainable Bioenergy Systems, 7, 65-84.

https://doi.org/10.4236/jsbs.2017.72006

Received: May 24, 2017

Accepted: June 18, 2017

Published: June 21, 2017

Copyright (ङ 2017 by authors and Scientific Research Publishing Inc. This work is licensed under the Creative Commons Attribution International License (CC BY 4.0).

http://creativecommons.org/licenses/by/4.0/

\begin{abstract}
An endophytic fungus producing 1,8-cineole from Neolitsea pulchella (Meissn.) Merr. was identified as Annulohypoxylon sp. by phylogenetic analyses of the sequence alignments of ITS rDNA, $\beta$-tubulin, Actin and EF1- $\alpha$. This isolate produces an attractive spectrum of volatile organic compounds (VOCs) with only one dominant component, 1,8-cineole, as identified by gas chromatography-mass spectrometry (GC-MS). The fungus was able to grow in seven media with different carbon sources, and five raw agro-forest residues. The content of 1,8-cineole in the mixed VOCs via fungus reached up to $94.95 \%$ and $91.25 \%$ relative area in PDA and raw poplar sawdust, respectively. Under optimum test conditions, the fungus produced 1,8 -cineole at the 0.764 ppmv in $50 \mathrm{~mL}$ head spaces in PDA. Interestingly, 1,8-cineole is an ideal fuel additive for both diesel and gasoline engines. Also, this is the first isolate, in this group of fungi, making cineole, which produces as its primary VOC product which makes it an ideal organism for strain improvement. Such as step will be critical for its ultimate use in biofuel production.
\end{abstract}

\section{Keywords}

1,8-Cineole, Agro-Forest Residues, Endophytic Annulohypoxylon, Biofuel, Fungal VOCs

\section{Introduction}

It is estimated that less than $5 \%$ of the fungal species on the earth have been found and described [1]. Endophytic fungi occupy a significant proportion of 
untold numbers of potential novel fungal genera [2]. When morphological data are missing, one can use internal transcribed spacer (ITS) sequence data to aid in identification fungi [3] [4] [5]. For difference strains, the reliability of ITS identification alone is questionable [4] [5]. In recent years, multiple gene loci and even whole genome have been developed which greatly helps in organismal identification [3] [4] [5]. Endophytic fungi are suitable for the discovery of new chemical entities including enzymes, and useful volatile organic compounds [6] [7] [8] [9] [10]. There are many methods to identify these volatile organic compounds, such as stainless steel column carbotrap technology [11], proton transfer reaction mass spectrometry (PTR-MS) [12], nuclear magnetic resonance spectroscopy [13] and headspace solid phase microextraction combined with gas chromatography-mass spectrometry (HS-SPME-GC-MS) [14]. Among them, HS-SPME-GC-MS is advanced in the analysis of volatile compounds in gas producing fungi because of its simplicity and speed.

The applications of endophytes producing novel bioactive products are gradually expanding in industry, medicine, food and other industries [7] [15] [16]. As an example, in recent years, some endophytic fungi, grown on waste wood fibers, produce some volatile organic compounds (VOCs) which are identical to compounds found in fossil fuels [16] [17]. These kinds of VOCs could represent the next generation of biomass produced compounds energy for the entire world. 1,8-Cineole, usually derived from plants [18] [19], has potential value as a fuel additive or even as a fuel. It improves the octane value of the ethanol gasoline blended fuel [20] [21], which solves the problem of poor energy density of ethanol that is also a fermentation product. Thus, 1,8-cineole has a great advantage for use in internal combustion and diesel run engines [17]. 1,8-Cineole is a monoterpenes and it is colorless liquid with an odor similar to that of camphor. 1,8-Cineole is usually extracted from leaves and branches of Eucalyptus tree species by distillation. Recently, 1,8-cineole has been discovered from a number of endophytic fungi including Nodulisporium sp. [1], Hypoxylon sp. [9], Annulohypoxylon sp. [22] and Acremonium sp. [23]. Compared with the previously reported fungi, a new strain FPYF3050 from Annulohypoxylon in this report produces 1,8 -cineole as a single dominant volatile in experimental media and on several agro-forest residues substrates. It holds promise as the most potent microbial resource for 1,8 cineole production.

\section{Materials and Methods}

\subsection{Endophytic Fungal Isolation}

The endophytic fungus was isolated from branches of Neolitsea pulchella (Meissn.) Merr. (Lauraceae) growing in the Jianfengling tropical rain forest of Hainan province at $\mathrm{E} 108^{\circ} 83^{\prime} ; \mathrm{N} 18^{\circ} 70^{\prime}$, Fungal isolation procedures followed the methods described by Ezra [24] and Arnold [25]. Briefly, external tissues were thoroughly exposed to $95 \%$ ethanol for 10 seconds prior to excision of internal tissues and 10\% Clorox agitated for 2 minutes. Then the draining tissues were agitated in $70 \%$ ethanol for 2 minutes. The excised small internal tissues were 
agitated in sterile water for 15 seconds and cultured on water agar of standard Petri dishes and further purified on potato dextrose agar media. The pure isolate was stored by barley seeds for supporting mycelia growth in the sterile water at $4^{\circ} \mathrm{C}$. The fungus of interest was labeled ID FPYFF3050 and stored at Yan's laboratory and China General Microbiological Culture Collection (CGMCC) with the number of 12771.

\subsection{Phylogenetic Analysis of Endophytic Fungus}

The FPYF3050 strain is in a sterile (not producing spores) stage under laboratory conditions. Its taxonomic information was determined on phylogenetic inference using molecular techniques. The mycelium from FPYF3050 colony in PDA for 6 days was harvested and the genomic DNA extracted using modified CTAB [26]. Fungal universal primers for ITS1/4 [27], EF1-983F/EF1-2218R [28], $\beta$-tubulin [29], Actin-512F/783R [30] seen in Supplementary Table S1. PCR amplification on the sequences was performed with the $25 \mu \mathrm{L}$ reaction system containing $0.5 \mu \mathrm{L}$ of each primer $(10 \mu \mathrm{M}), 3.0 \mu \mathrm{L}$ of DNA template, $12.5 \mu \mathrm{L}$ of $2 \times$ Taq PCR MasterMix (TIANGEN BIOTECH), $8.5 \mu \mathrm{L}$ of double distilled water. The ITS thermal cycling program was as follows: $94^{\circ} \mathrm{C}$ for $3 \mathrm{~min}$, followed by 35 amplification cycles of $94^{\circ} \mathrm{C}$ for $30 \mathrm{~s}, 52^{\circ} \mathrm{C}$ for $45 \mathrm{~s}$ and $72^{\circ} \mathrm{C}$ for $1 \mathrm{~min}$, and a final extension step of $72^{\circ} \mathrm{C}$ for $10 \mathrm{~min}$. Only the annealing temperature was changed in this program for Actin, $\beta$-tubulin and EF1- $\alpha$ amplification with at $61^{\circ} \mathrm{C}, 55^{\circ} \mathrm{C}$ and $63^{\circ} \mathrm{C}$, respectively.

PCR products were sequenced by the Sunbiotech Company in Beijing, and sequences were submitted to GenBank. Sequences obtained in this study were compared to the National Center for Biotechnology Information (NCBI) database using the BLASTn software. According to the results of BLASTn, DNA reference sequence data were chosen for phylogenetic analysis, which were from three genera, Annulohypoxylon, Hypoxylon and Daldinia. Bayesian inference [31] was used for the phylogenetic analyses of our DNA sequence data. The sequences were aligned by MAFFT 7.304 [32]. Phylogenetic analyses of the aligned sequences were performed with MrBayes3.2.2. For Bayesian analyses, the settings were "invgamma shape", "one substitution" and "NY98". The number of generations was set to $1,000,000$, and one tree was saved per 100 generations. The first $20 \%$ of the trees were excluded from construction of the consensus tree. The cladogram and posterior credibility values for the clades found were based on the outcome of the last 0.8 million generations. All the phylogenetic trees were rooted using Biscogniauxia atropunctata as outgroup. Evidence on the trees were combined and visualized by TreeGraph 2 [33].

\subsection{Qualitative Analysis of FPYF3050 VOCs Grown on Selected Substrates}

A variety of selected media were used to determine which substrates can facilitate 1,8-cineole production by FPYF3050. The media used for the testing were divided into three types. The first was common laboratory medium including potato dextrose agar (PDA), Czapek's agar (CA) [34], oatmeal agar (OA) [35] 
and malt extract agar (MEA) [36]. The second was synthetic medium described by Mallette [37] including cellulose medium (CM), carboxymethyl cellulose (CMC) and glucose medium (GM) as carbon sources. The third type was agriculture and forestry residue medium including poplar sawdust, pine sawdust, corn straw, rice straw and wheat straw. The five kinds of raw agriculture and forestry residues were rinsed by tap water, and then cleanly washed with ddH2O, the last soaked in sterile water for 2 hours to fully absorb water. Then wet sawdust and straw without dropping water were autoclaved to be medium. The cultural conditions for the strain FPYF3050 was at $25^{\circ} \mathrm{C}$ constant temperature for 6 days. All samples were examined in triplicate.

Analyses of gases in the air space above FPYF3050 colony in Petri plates were conducted according to the following protocol as described papers [9] [37]. A baked fiber syringe of 50/30 divinylbenzene/carboxen on polydimethylsiloxane (Supelco) was exposed to the vapor phase inside Petri for $40 \mathrm{~min}$ through a small hole $(0.6 \mathrm{~mm}$ in diameter) drilled on the sides of the Petri plate. Then the syringe was inserted into the splitless injection port of a Thermo Finnigan gas chromatograph containing a $30.0 \mathrm{~m} \times 0.25 \mathrm{~mm}$ HP-5MS capillary column with a film thickness of $0.25 \mathrm{~mm}$. A $30 \mathrm{~s}$ injection time was used to introduce the sample fiber into the GC. The column was temperature programmed as follows: $33^{\circ} \mathrm{Cfor}$ 2 min increased to $220^{\circ} \mathrm{C}$ at $5^{\circ} \mathrm{C} \cdot \mathrm{min}^{-1}$. The MS (TRACE DSQ) was scanned at a rate of 5 scans per second over a mass range of 41 - $560 \mathrm{amu}$. Control PDA Petri plates uninoculated with the strain were used to subtract compounds contributed by the medium. All treatments and checks were done in triplicate. Tentative identification of the compounds produced by FPYF3050 was made against NIST compounds library with GC, and all chemical compounds were described in this report following the NIST database chemical terminology.

\subsection{Quantification of 1,8-Cineole by GC-FID}

Quantification of 1,8-cineole was done in the air space above cultures of FPYF3050 grown for $1-6$ days at $25^{\circ} \mathrm{C}$ on PDA (Petri size $9 \mathrm{~cm}$ and head space volume is $50 \mathrm{ml}$ ). The GC analysis was executed using a Agilent 7980 equipped with an FID detector, HP-5MS column $(30.0 \mathrm{~mm} \times 0.25 \mathrm{~mm}$, film thickness 0.25 $\mu \mathrm{m})$. The operating conditions were oven temperature $33^{\circ} \mathrm{C}(2 \mathrm{~min}), 33^{\circ} \mathrm{C}-$ $220^{\circ} \mathrm{C}\left(7^{\circ} \mathrm{C} / \mathrm{min}\right), 220^{\circ} \mathrm{C}(7 \mathrm{~min})$; injector temperature $240^{\circ} \mathrm{C}$, with the tail blowing gas $\mathrm{N}_{2}(39 \mathrm{ml} / \mathrm{min})$; detector temperature $250^{\circ} \mathrm{C}, \mathrm{H}_{2}: \mathrm{O}_{2}$ is $40: 400$ $\mathrm{ml} / \mathrm{min}$. All compounds with a quality match of $60 \%$ and above were recorded.

The standard 1,8-cineole (Fluka) was diluted 10 times in 5 concentrations with hexane ranging 0.005 to $50 \mu \mathrm{L} / \mathrm{ml}$. Each standard 1,8-cineole concentration contained linalool (internal standard, Fluka) of the same concentration at 0.5 $\mu \mathrm{L} / \mathrm{ml}$. The calibration curve was found with As/Ai (standard peak area /internal standard peak area) as transverse coordinate and Vs/Vi (standard volume/internal standard volume) as longitudinal coordinate, and calculated relative mass calibration factor $\mathrm{F}\left(\mathrm{F}=\left(\mathrm{Ai}^{\star} \mathrm{Vs}\right) /\left(\mathrm{As}{ }^{\star} \mathrm{Vi}\right)\right)$. The calibration curve was linear and passed through the origin. 
Parameters and conditions during the HS-SPME process and final quantification by GC-FID were same as HS-SPME-GC-MS previously. Triplicates were for each sample. The contents of 1,8-cineole in the sample were calculated according to the calibration curve. Then mycelium in the culture Petri dish after GC-FID quantification was dried at $60^{\circ} \mathrm{C}$ to obtain the dry weight of mycelium. The deviations for dry weights for one colony were less than $0.0001 \mathrm{~g}$ among the three individual weightings.

\section{Results and Discussion}

\subsection{Isolation and Identification of Endophytic Fungus}

The isolate FPYF3050 fungus was recovered from the healthy branches of a Lauraceae tree, Neolitsea pulchella (Meissn.) Merr. The strain produces a white flocculent mycelium and forms round colonies in the early stage on PDA medium (Figure 1). Small pieces of black thin flakes occurred on the colonies at 4days old (Figure 1(A)). As the colonies mature, the flakes aggregate and cover the colony with the more blackish green pigments ultimately yielding a black coloration at the bottom of the colony. The pigment secretions gradually dispersed through the whole medium. Thus, the medium is stained black with the increasing culture time (Figure $1(B)$ ). Finally, the black thin flakes cover the colony surface and the back of the culture medium turns black (Figure 1(B)). No sporulation of the fungus was observed in the laboratory. As no spores or fruiting structures were formed, molecular techniques were exclusively used to help with the identification of the fungus. Thus, four phylogenetic molecular

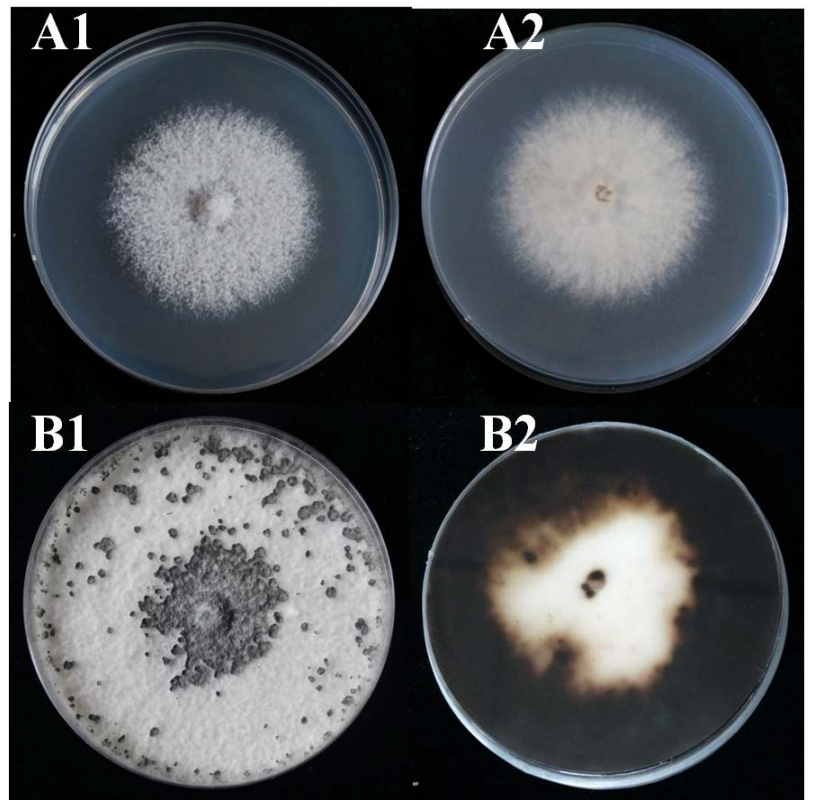

Figure 1. Morphological characteristics of FPYF3050 on PDA. A is 4-day colony morphological characteristics on PDA. A1 is the obverse and A2 is the reverse. The mycelium is villiform. B is 30-day colony morphological characteristics on PDA. B1 is the obverse and B2 is the reverse. Small black thin flakes occur on colony and the medium is stained into black by pigment. 
sequences were completed on this fungus consisting of ITS-5.8S-rDNA, $\beta$-tubulin, EF1- $\alpha$ and Actin. Each of these sequences was deposited in GenBank with IDs KX578223, KX592160, KX708697and KX592161, respectively.

More than 200, 140 and 100 referenced sequences for the ITS, $\beta$-tubulin and Actin from the NCBI database were used to be involved in the development of the phylogenetic trees, respectively. Each phylogenetic tree is seen partly in Figures 2-4 for limited space.

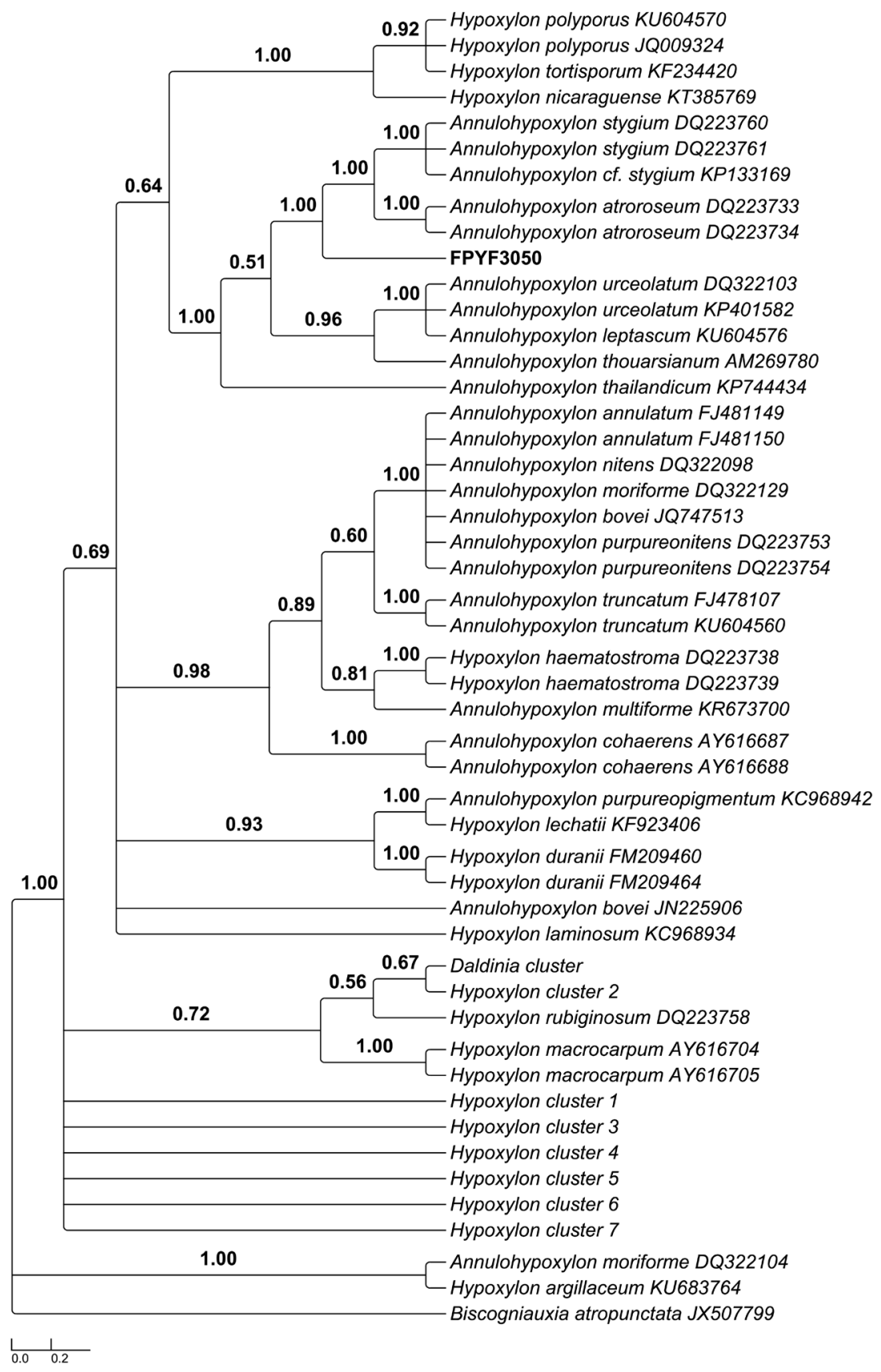

Figure 2. A phylogenetic tree generated by Bayesian analysis from ITS dataset. The phylogenetic tree was rooted using Biscogniauxia atropunctata as outgroup. Bayesian posterior probability values greater than $50 \%$ are shown above branches and species clustering is noted. 


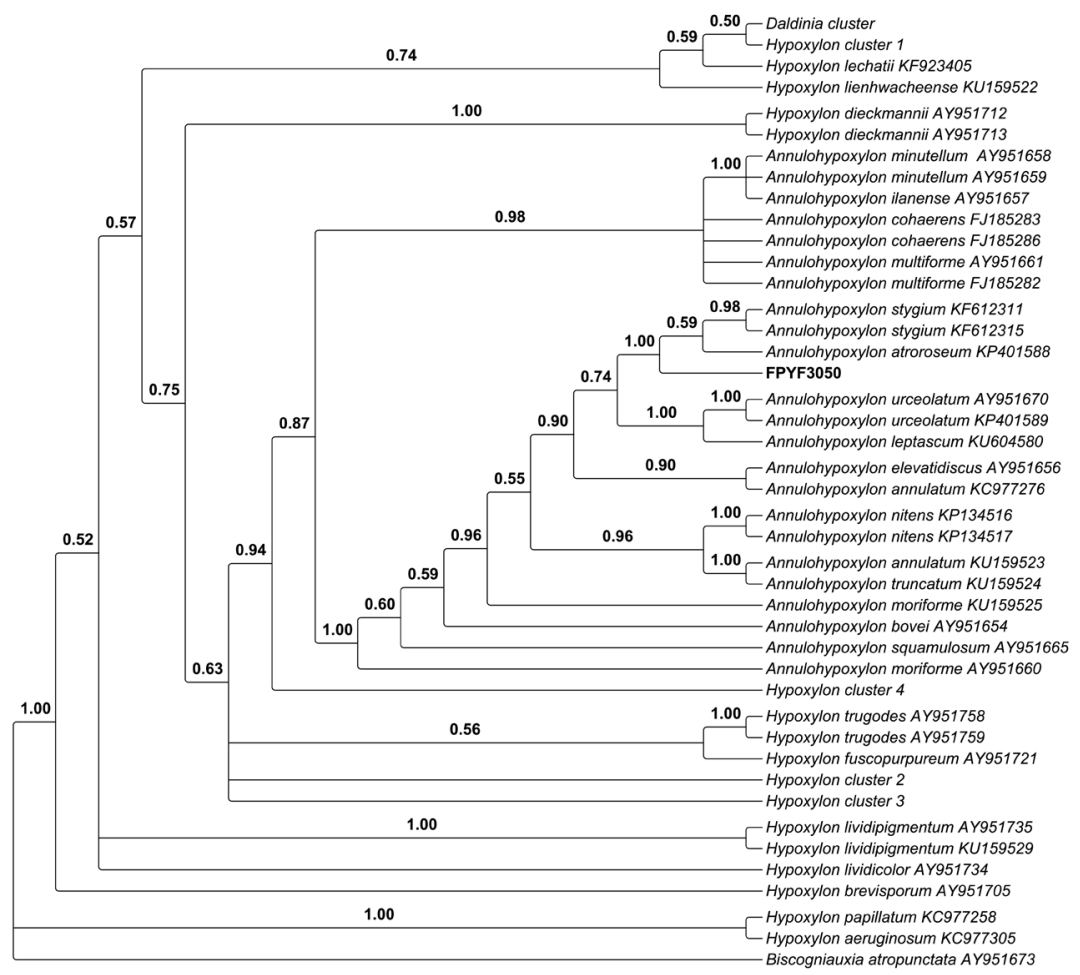

b. $\quad 1$

Figure 3. A phylogenetic tree generated by Bayesian analysis from $\beta$-tubulin dataset. The phylogenetic tree was rooted using Biscogniauxia atropunctata as outgroup. Bayesian posterior probability values greater than $50 \%$ are shown above branches and species clustering is noted.

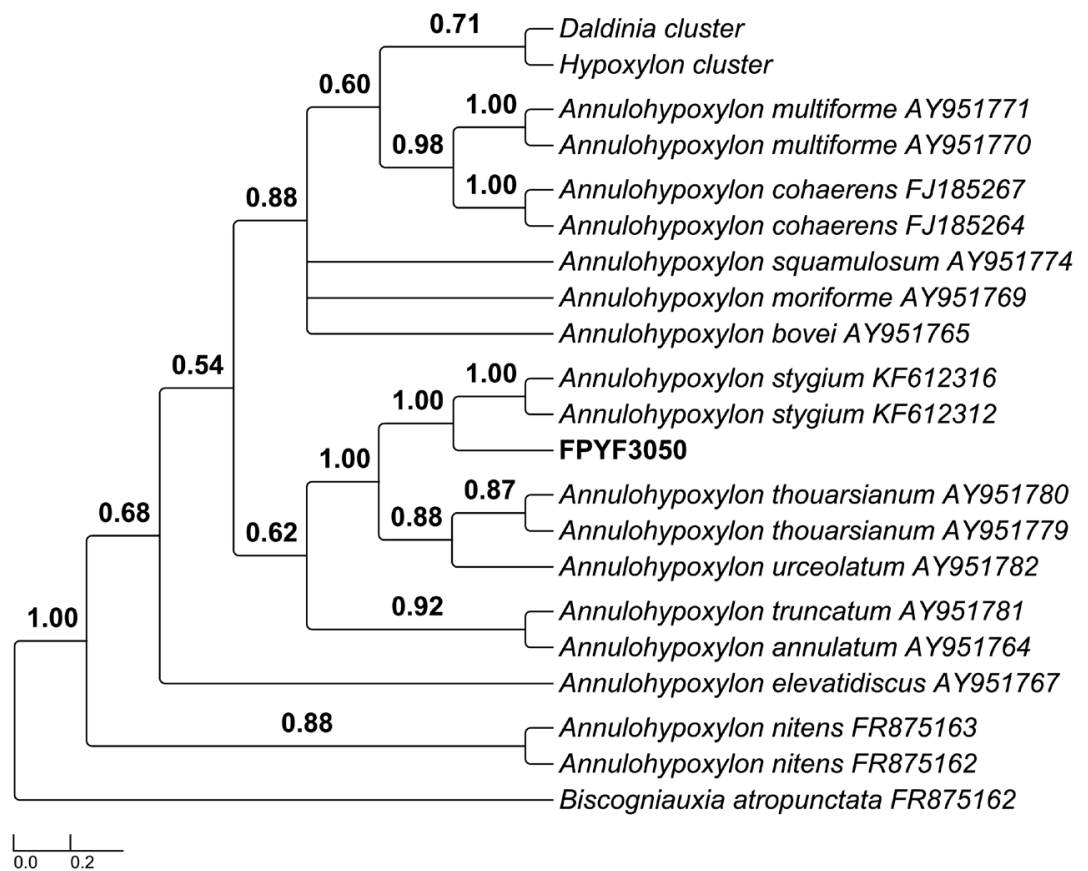

Figure 4. A phylogenetic tree generated by Bayesian analysis from Actin dataset. The phylogenetic tree was rooted using Biscogniauxia atropunctata as outgroup. Bayesian posterior probability values greater than $50 \%$ are shown above branches and species clustering is noted. 
Due to few EF1- $\alpha$ referring sequences in NCBI database, the phylogenetic tree of the EF1- $\alpha$ was not constructed. However, the best hits of the EF1- $\alpha$ of the strain queried in NCBI were Annulohypoxylon nitens and Annulohypoxylon sp. isolate PK09007 with the identities of $93 \%$ and $92 \%$ by the BLAST program. The result of this molecular methodology placed the identity of the isolate FPYF3050 fungus squarely in the perfect stage genus of Annulohypoxylon. It is to be further noted that the imperfect stage of this fungus is Nodulisporium which can occur among all of the perfect stages of Annulohypoxylon, Hypoxylon, Xylaria and Daldinia. Thus, in this report we refer to it as Annulohypoxylon sp. FPYF3050.

Annulohypoxylon was created as a new genus from Hypoxylon with ostioles and ascospora morphology and molecular phylogenety in 2005 [5] [38]. Annulohypoxylon is divided into two subclades based on the presence or absence of ostiolar disks [5]. In this study, the strain, FPYF3050, isolated as an endophytic fungus without any spores or other fruiting structures to characterize it, was characterized using its operational taxonomic units (OTU) species by four phylogenetic loci. Although ITS sequencing has become an effective and important marker for fungal molecular evolution and phylogeny [3] [4] ITS sequences did not exclusively separate Annulohypoxylon and Hypoxylon [5]. Therefore, protein-encoding sequences, $\beta$-tubulin, Actin and EF1- $\alpha$, were also involved in the identification of the strain. The Bayes inference of phylogenetic analyses on $\beta$ tubulin and Actin ascribed the strain into Annulohypoxylon genus, closely clustered with $A$. strugium and A. atroroseum (Figures 2-4) with the support of $100 \%$ posterior probability. The fungi in Daldinia and Hypoxylon clusters have greater genetic distances with the strain. Phylogenetic inference was not developed with EF1- $\alpha$ for the strain due to so few reference strains sequences in NCBI databases for Annulohypoxylon fungi. However, the results queried with EF1- $\alpha$ sequence of FPYF3050 also hit the highest homolog sequences from Annulohypoxylon species by the Blastn program. Therefore, based on all of the available data the strain was assigned as an Annulohypoxylon sp.

\subsection{VOCs Qualitative Analyses of Annulohypoxylon sp. FPYF3050}

The fungus produced diverse volatiles on different media were showed in Table 1 and Table 2, and their respective GC/MS profiles are showed on Supplementary Figure S1 and Figure S2. These volatiles mainly contained alkenes, alcohols and several unknown ingredients. The products appearing were relatively consistent when the fungus was grown on CA, CMC, CM and OA media (Table 1). GM medium induced the strain to produce more VOCs (Table 1). In PDA and MEA media the fungus produced only 4 and 6 compounds, respectively (Table 1). On the five raw agro-forest residue media, poplar, pine, corn, wheat and rice (Figure 5), the endophytic fungal Annulohypoxylon sp. produced 5, 11, 17, 14 and 7 kinds of volatile compounds, respectively (Table 2). The significant difference of these five kinds of agro-forest residue media is their carbon sources. The main carbon sources of poplar and pine are the lignocelluloses, and the 
Table 1. A GC/MS air-space analysis of the volatile compounds was produced by FPYF3050 on 7 medium using a SPME fiber. The diameter of initial inoculums plug is $5 \mathrm{~mm}$. The strain FPYF3050 was at $25^{\circ} \mathrm{C}$ constant temperature for 6 days. Compounds found in the control Petri plate are not included in this table.

\begin{tabular}{|c|c|c|c|c|c|c|c|c|c|c|c|c|c|c|c|c|}
\hline \multirow{2}{*}{$\begin{array}{l}\text { Retention } \\
\text { time } \\
(\mathrm{min})\end{array}$} & \multirow{2}{*}{ Possible compound } & \multirow{2}{*}{$\begin{array}{l}\text { Mol. } \\
\text { mass- } \\
(\mathrm{Da})\end{array}$} & \multicolumn{9}{|c|}{ Quality match (\%) } & \multicolumn{5}{|c|}{ Relative area (\%) } \\
\hline & & & GM & $\mathrm{CA}$ & $\mathrm{CMC}$ & $\mathrm{CM}$ & $\mathrm{OA}$ & MEA & PDA & GM & $\mathrm{CA}$ & $\mathrm{CMC}$ & $\mathrm{CM}$ & $\mathrm{OA}$ & MEA & PDA \\
\hline 1.80 & 1,2-Propanediamine & 74 & l & l & l & l & l & 60 & l & l & I & l & l & l & 0.05 & I \\
\hline 2.33 & $\begin{array}{c}\text { 1,3-Propanediol, } \\
\text { 2-ethyl-2-(hydroxymethyl)- }\end{array}$ & 134 & I & 1 & 64 & l & 1 & 1 & I & I & I & 3.54 & 1 & 1 & 1 & 1 \\
\hline 2.62 & Unknown* & 184 & l & l & l & l & l & l & l & l & l & I & 4.79 & l & l & l \\
\hline 4.32 & 1-Butanol,3-methyl & 88 & l & l & l & I & l & I & 89 & I & l & I & I & I & I & 2.37 \\
\hline 5.01 & Toluene & 92 & 70 & 64 & 78 & 73 & 75 & I & l & 3.58 & 5.96 & 5.36 & 3.90 & 7.03 & I & I \\
\hline 7.35 & o-Xylene & 106 & l & 83 & l & l & l & I & l & l & 20.35 & l & l & I & I & l \\
\hline 8.89 & $\begin{array}{l}\text { Bicyclo[3.1.0]hex-2-ene, } \\
\text { 4-methyl-1-(1-methylethyl) }\end{array}$ & 136 & I & 1 & I & l & l & 1 & 91 & l & I & I & l & l & l & 1.17 \\
\hline 9.03 & $\alpha$-Phellandrene & 136 & l & l & l & l & l & 83 & l & l & I & l & l & l & 2.10 & I \\
\hline 9.73 & Unknown & 120 & I & l & l & I & l & I & l & I & 10.25 & 17.90 & 13.99 & 9.30 & I & I \\
\hline 11.36 & Benzene, 1,4-dichloro- & 146 & I & 79 & 81 & 76 & I & 1 & l & I & 15.09 & 17.94 & 19.00 & I & I & I \\
\hline 11.40 & $\begin{array}{c}\text { Cyclohexene, } \\
\text { 1-methyl-4-(1-methylethylidene)- }\end{array}$ & 136 & I & l & l & l & l & 61 & l & l & l & I & I & I & 1.65 & I \\
\hline 11.85 & 1,8 -cineole & 154 & 81 & I & l & I & 78 & 89 & 93 & 32.33 & I & I & l & 19.42 & 93.69 & 94.95 \\
\hline 12.26 & $\gamma$-Terpinene & 136 & I & 1 & 1 & 1 & I & 82 & 93 & I & 1 & 1 & I & I & 1.26 & 1.51 \\
\hline 12.83 & Unknown & 238 & l & 1 & I & l & l & I & I & 2.40 & I & I & l & I & I & I \\
\hline 14.59 & Camphor & 152 & l & 80 & 78 & 77 & 78 & l & l & I & 7.52 & 8.39 & 10.16 & 8.77 & I & I \\
\hline 14.59 & $(+)$-2-Bornanone & 152 & 76 & I & l & I & I & I & I & 5.42 & I & I & I & I & I & I \\
\hline 18.07 & Naphthalene, 1-methyl- & 142 & 62 & l & l & 1 & l & I & I & 1.56 & I & l & I & l & I & I \\
\hline 19.76 & Unknown & 204 & I & l & 1 & 1 & l & 1 & l & 1.06 & l & 1 & l & I & I & l \\
\hline 19.95 & Tetradecane & 198 & I & 62 & 68 & 62 & 68 & l & l & & 4.65 & 5.55 & 4.99 & 6.14 & l & I \\
\hline 19.96 & Ditetradecyl ether & 410 & 61 & l & l & I & l & I & I & 2.97 & l & I & l & I & I & I \\
\hline 20.70 & $\begin{array}{l}\text { Bicyclo[3.1.1]hept-2-ene, } \\
\text { 2,6-dimethyl-6- } \\
\text { (4-methyl-3-pentenyl)- }\end{array}$ & 204 & 66 & l & l & I & l & l & l & 4.51 & l & l & l & l & I & I \\
\hline 21.11 & Unknown & 366 & l & l & l & l & l & l & l & 5.98 & l & l & I & l & I & I \\
\hline 21.73 & $\begin{array}{l}\text { 1H-3a,7-Methanoazulene, octahy- } \\
\text { dro-3,8,8-trimethyl-6-methylene-, } \\
\quad[3 \mathrm{R}-(3 \alpha, 3 \mathrm{a} \beta, 7 \beta, 8 \mathrm{a} \alpha)]-\end{array}$ & 204 & 77 & l & l & l & l & l & I & 21.20 & I & I & l & l & I & I \\
\hline 21.85 & $\begin{array}{c}\text { cis-(-)-2,4a,5,6,9a-Hexahydro-3,5,5,9- } \\
\text { tetramethyl }(1 \mathrm{H}) \text { benzocycloheptene }\end{array}$ & 204 & l & l & I & l & l & 76 & I & l & l & l & l & l & 1.26 & l \\
\hline 21.91 & Pentadecane & 212 & 66 & 71 & 69 & 68 & 72 & l & l & 7.24 & 12.21 & 12.40 & 12.99 & 23.36 & I & 1 \\
\hline 22.06 & Butylated Hydroxytoluene & 220 & 1 & 70 & 74 & 70 & l & l & l & l & 13.11 & 22.16 & 24.18 & I & I & 1 \\
\hline 22.87 & Unknown & 240 & 1 & 1 & I & I & l & I & I & 1.88 & I & I & I & 1 & I & 1 \\
\hline 22.98 & Unknown & 348 & I & I & I & I & 1 & I & I & 2.15 & I & I & I & 1 & I & I \\
\hline 23.09 & Unknown & 284 & I & I & 1 & I & I & I & 1 & 1 & I & I & I & 2.75 & I & I \\
\hline 23.09 & Unknown & 448 & I & I & I & I & I & I & I & 1.98 & I & I & I & I & I & 1 \\
\hline
\end{tabular}




\begin{tabular}{|c|c|c|c|c|c|c|c|c|c|c|c|c|c|c|c|c|}
\hline \multicolumn{17}{|c|}{ Continued } \\
\hline 23.75 & Pentacosane & 352 & 64 & I & 1 & 1 & 1 & I & I & 4.06 & I & l & I & I & I & I \\
\hline 23.76 & Hexadecane & 226 & I & 70 & 64 & 63 & 73 & I & I & 1 & 6.19 & 6.77 & 5.99 & 1.37 & I & I \\
\hline 24.56 & Unknown & 298 & I & I & I & I & 1 & I & l & 1.66 & I & 1 & I & 1 & I & I \\
\hline 25.04 & $\begin{array}{c}\text { Azulene, } \\
\text { 1,2,3,3a,4,5,6,7-octahydro-1,4-dimet } \\
\text { hyl-7-(1-methylethenyl)-, } \\
\text { [1R-(1 } 1 \alpha, 3 \mathrm{a} \beta, 4 \alpha, 7 \beta)]-\end{array}$ & 204 & I & I & I & 1 & 73 & I & I & 1 & I & I & I & 17.84 & I & I \\
\hline 25.04 & $\begin{array}{l}\text { Tricyclo[7.2.0.0(2,6)] undecan-5-ol, } \\
\text { 2,6,10,10-tetramethyl-(isomer 2) }\end{array}$ & 222 & 62 & I & 1 & I & I & 1 & 1 & 2.76 & 1 & I & I & I & 1 & I \\
\hline 25.05 & Hinesol & 222 & l & 65 & I & I & I & I & l & I & 4.67 & I & I & I & I & I \\
\hline 25.55 & Unknown & 366 & I & I & I & I & I & I & l & I & I & I & I & 4.01 & I & I \\
\hline \multicolumn{10}{|c|}{ Number of VOC } & 17 & 10 & 9 & 9 & 10 & 6 & 4 \\
\hline
\end{tabular}

*unknown is the content with quality match lower than 60 .

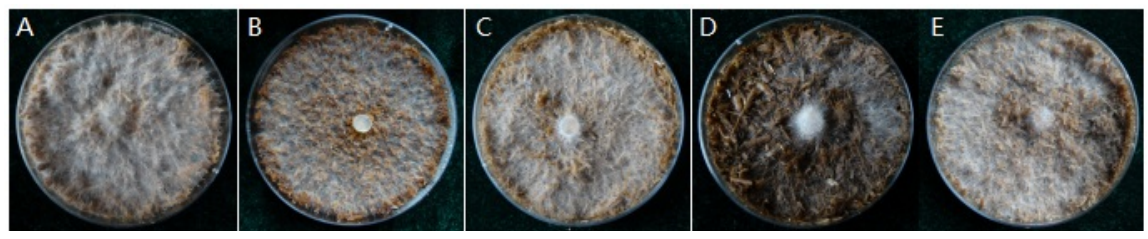

Figure 5. Morphological characteristics of Annulohypoxylon FPYF3050 on five kinds of agro-forest residue media. A is Poplar medium. B is Pine medium .C is Corn medium. D is Wheat medium. E is Rice medium. The cultural condition for the strain FPYF3050 was in $25^{\circ} \mathrm{C}$ constant temperature for 6 days.

primary carbon source in wheat, corn and rice is cellulose. 1,8-Cineole was found to be the most abundant compound in the fungal VOCs with poplar, wheat, corn, pine, PDA and MEA (Table 1 and Table 2). There was no 1,8-cineole found in CA,CM ,CMC and rice media (Table 1 and Table 2) even though there was fungal growth. This does indicate that glucose, cellulose, carboxymethyl cellulose and rice straw are not effective substrates for the production of 1,8 cineole by the fungus. Also, different substrates had great influence on the yield of 1,8-cineole. The natural media such as PDA and MEA were better substrates 1,8-cineole of Annulohypoxylon sp. production than synthetic media such as CA, CM and CMC (Table 1). On four agro-forest residues, poplar, pine, wheat and corn, the fungal 1,8-cineole yielded up $91.25 \%, 57.72 \%, 29.09 \%$ and $29.44 \%$ of the VOC mix, respectively (Table 2). On the basis of the relative output, the lignocelluloses are the most conducive to the production of 1,8-cineole.

\subsection{1,8-Cineole Quantity Analyses on Annulohypoxylon sp. FPYF3050}

For the quantity analyses, a calibration curve was built with the data of GC-FID with $\mathrm{R}=0.9995$ by the formula, $\mathrm{y}=0.8674 \mathrm{x}-0.7735$, between linalool (internal standard) and 1,8-cineole (standard). It demonstrated that 1,8-cineole in the sample could be quantified using linalool as the internal standard. The value of $\mathrm{F}$ was 0.85 . Trial experiments showed that the highest yield of 1,8-cineole was 
Table 2. A GC/MS air-space analysis of the volatile compounds was produced by FPYF3050 on 5 agro-forest residue medium using a SPME fiber. The diameter of initial inoculums plug is $5 \mathrm{~mm}$. The strain FPYF3050 was at $25^{\circ} \mathrm{C}$ constant temperature for 6 days. Compounds found in the control Petri plate are not included.

\begin{tabular}{|c|c|c|c|c|c|c|c|c|c|c|c|c|}
\hline \multirow{2}{*}{$\begin{array}{l}\text { Retention } \\
\text { time } \\
(\min )\end{array}$} & \multirow{2}{*}{ Possible compound } & \multirow{2}{*}{$\begin{array}{l}\text { Mol. } \\
\text { mass } \\
(\mathrm{Da})\end{array}$} & \multicolumn{5}{|c|}{ Quality match (\%) } & \multicolumn{5}{|c|}{ Relative area (\%) } \\
\hline & & & Poplar & Pine & Corn & Wheat & Rice & Poplar & Pine & Corn & Wheat & Rice \\
\hline 5.01 & Unknown $^{*}$ & 207 & I & I & I & 1 & 1 & I & I & I & 2.68 & I \\
\hline 5.39 & Bicyclo[3.2.0]hept-6-ene & 94 & I & I & I & 61 & 1 & I & I & l & 1.18 & / \\
\hline 6.20 & 2-Methyl-7-phenylindole & 207 & 1 & 62 & l & 71 & 1 & I & 3.54 & l & 10.87 & I \\
\hline 7.33 & Unknown & 106 & 1 & I & I & I & I & I & l & 0.73 & I & I \\
\hline 7.36 & Unknown & 106 & 1 & l & l & l & l & l & 0.65 & l & l & l \\
\hline 9.20 & Bicyclo[3.1.1]hept-2-ene, 3,6,6-trimethyl- & 136 & l & 66 & l & l & l & l & 1.2 & l & l & l \\
\hline 9.77 & Unknown & 209 & l & l & l & l & l & l & l & I & 1.11 & l \\
\hline 10.03 & Benzaldehyde & 106 & 76 & 79 & l & l & l & 1.47 & 12.94 & l & I & l \\
\hline 10.39 & $\begin{array}{c}\text { Molybde- } \\
\text { num,bis }[(1,2,3,4,5,6-\eta) \text {-methylbenzene }]-\end{array}$ & 282 & l & l & l & 61 & I & l & l & I & 17.16 & I \\
\hline 10.40 & Dibenz[a,h]anthracene, 5,6-dihydro- & 280 & 1 & l & 62 & l & l & l & l & 1.49 & I & l \\
\hline 11.36 & Unknown & 236 & l & l & l & l & l & I & l & 21.62 & l & l \\
\hline 11.38 & Benzenemethanol, 3,5-dimethyl- & 136 & 69 & l & l & l & l & 1.72 & l & l & l & l \\
\hline 11.75 & $\begin{array}{l}\text { 3(2H)-Isoquinolinone, octahydro-, } \\
\text { (4ar-trans)- }\end{array}$ & 153 & l & l & 1 & l & 65 & 1 & l & l & l & 44.25 \\
\hline 11.76 & 1,8 -cineole & 154 & 82 & 81 & 74 & 74 & l & 91.25 & 57.72 & 29.44 & 29.09 & I \\
\hline 12.41 & 2-Carene & 136 & 75 & l & l & l & l & 1.86 & l & l & I & I \\
\hline 12.82 & Unknown & 229 & 1 & l & l & I & l & I & 0.96 & 1 & l & l \\
\hline 12.83 & Unknown & 184 & l & l & l & l & l & l & l & l & l & 0.75 \\
\hline 12.84 & 3-Ethyl-2-pentadecanone & 254 & l & l & 70 & 68 & l & l & l & 4.3 & 14 & l \\
\hline 13.78 & Benzene, 1-ethyl-4-methoxy- & 136 & 1 & l & l & I & 66 & l & l & I & l & 2.2 \\
\hline 14.07 & Unknown & 354 & 1 & l & l & I & l & l & I & 0.9 & I & l \\
\hline 14.58 & Unknown & 138 & l & l & l & l & l & l & l & l & 6.25 & l \\
\hline 14.75 & Benzene, 1-ethenyl-4-methoxy- & 134 & 81 & l & 77 & l & 77 & 3.7 & l & 7.35 & / & 49.45 \\
\hline 14.95 & Unknown & 194 & l & l & l & I & l & l & l & l & 0.42 & I \\
\hline 15.79 & $2 \alpha, 4 \mathrm{a} \beta, 8 \mathrm{a} \beta$-Decahydro-2-naphthalenol & 154 & l & l & 61 & l & l & l & I & 0.34 & l & l \\
\hline 16.03 & $\begin{array}{l}\text { 2(1H)-Benzocyclooctenone, decahy- } \\
\text { dro-10a-methyl-, trans- }\end{array}$ & 194 & I & 61 & 1 & I & 1 & 1 & 3.37 & I & I & I \\
\hline 16.56 & Unknown & 344 & I & I & I & I & I & I & I & I & 0.35 & / \\
\hline 17.75 & Unknown & 432 & 1 & I & 1 & 1 & 1 & 1 & 1.5 & I & 3.47 & I \\
\hline 19.12 & Unknown & 204 & I & I & 1 & I & 1 & I & 1.03 & 1 & I & I \\
\hline 19.86 & $\begin{array}{c}\text { Naphtha- } \\
\text { lene, }, 2,3,5,6,7,8,8 \mathrm{a} \text {-octahydro-1,8a-dimethyl- } \\
\text { 7-(1-methylethenyl)-, [1S-(1 } \alpha, 7 \alpha, 8 \mathrm{a} \alpha)] \text { - }\end{array}$ & 204 & I & 1 & 67 & I & 1 & I & I & 1.11 & I & I \\
\hline 19.87 & Unknown & 204 & I & I & 1 & I & 1 & I & I & 1 & 3.44 & I \\
\hline 19.88 & Unknown & 204 & I & I & 1 & I & I & I & I & I & I & 0.84 \\
\hline 20.38 & $\gamma$-himachalene & 204 & I & 65 & I & I & 1 & I & 3.16 & I & I & I \\
\hline
\end{tabular}




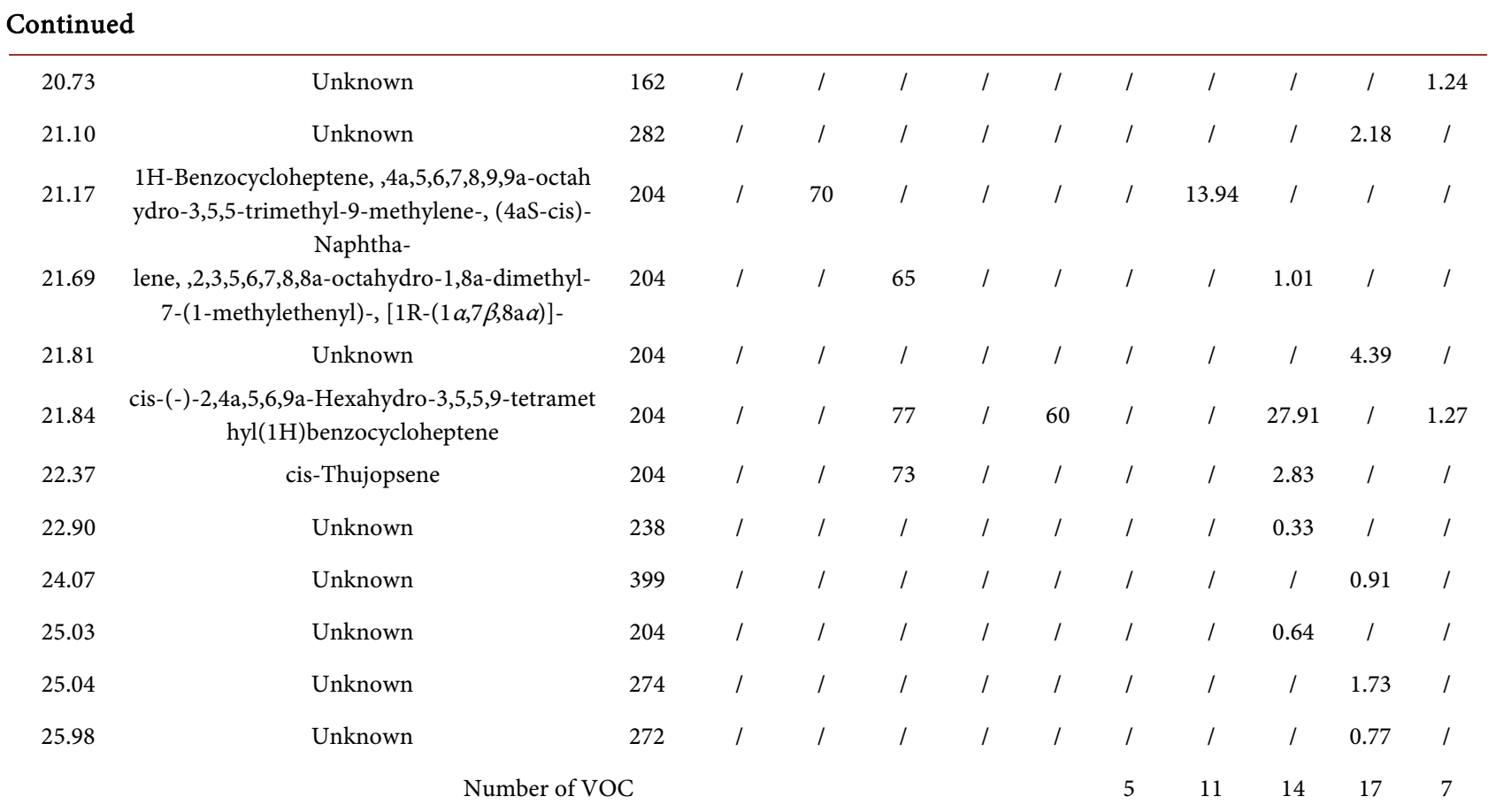

*unknown is the content with quality match lower than 60 .

achieved at the sixth day in the incubation period of this fungus under the outlined test conditions, and the yield began to decrease at the seventh day. Therefore, we acquired data of colony diameter, dry weight of mycelium and quantity of 1,8-cineole from 1 to 6 days on PDA (Supplementary Table S2). The highest production of 1,8-cineole was a 6-day-old culture of Annulohypoxylon sp. making $0.764 \mathrm{ppmv}$ in a $50 \mathrm{ml}$ air space of a Petri plate with $9 \mathrm{~cm}$ diameter. Analysis of 1,8-cineole yield was related to two factors, dry weight of mycelium and colony diameter and Supplementary Table S2 showed that they were linear relationships. The $\mathrm{R}$ value was 0.9974 for the linear relationship between dry weight of mycelium and 1,8-cineole yield (Figure 6).

The Annulohypoxylon sp. FPYF3050 strain produced exclusively VOCs with 1.8-cineole as the major product. Interestingly, it doesn't share the same VOCs profiles as with other endophytic fungi producing 1,8-cineole [1] [9] [22] [23]. In the PDA medium, the fungus produced 4-5 detectable volatile compounds compared to 29 VOCs with Hypoxylon sp. CI4A [9], 32 VOCs with Nodulisporium sp. [1], 15 VOCs with Annulohypoxylon sp. [22], 20 VOCs with Acremonium sp. R1, and 16 VOCs with Acremonium sp. R2 [23]. Thus, the Annulohypoxylon is unique among all of these strains relative to its ability to make mostly 1,8 -cineole in its mixture of VOCs. The content of 1,8-cineole in VOCs produced by FPYF3050 growing on PDA was up to $94.95 \%$ of the relative area (RA) according to GC-MS results (Table 1). However, the abundance of 1,8-cineole in VOCs produced by other endophytic fungi was lower than 30\% RA [1] [9] [22] [23]. In the case of Hypoxylon sp. CI4A, 1,8-cineole was represented as only $0.5 \%$ of the total VOCs [9]. The capability to produce highly abundant 1,8 -cineole by the fungus is maintained in different substrates, such as in MEA with 

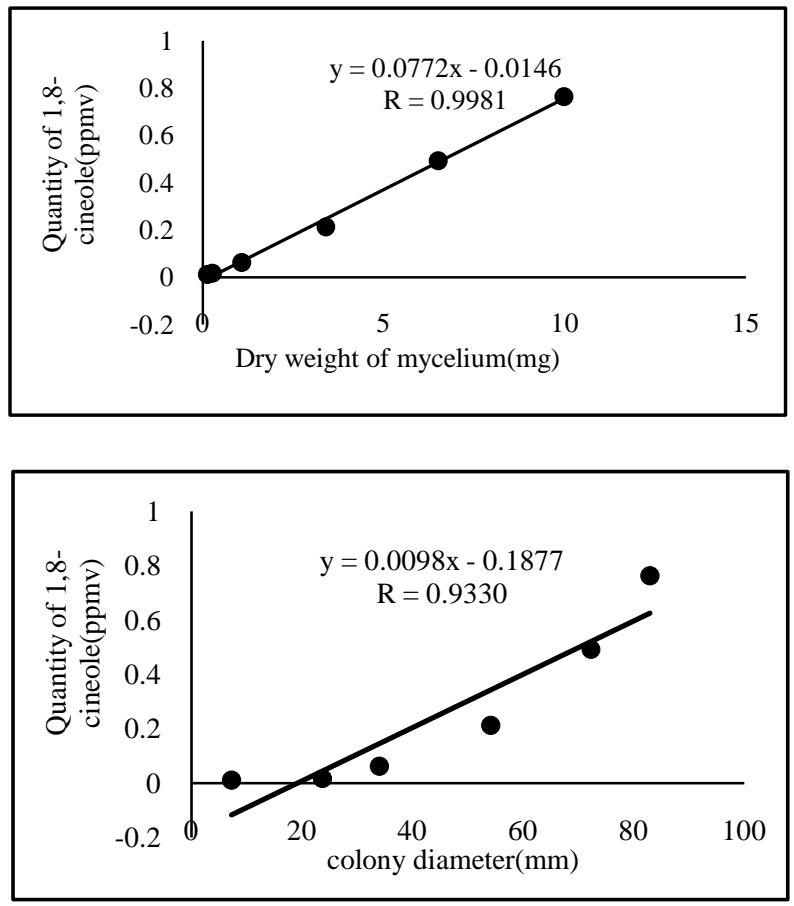

Figure 6. Relationship between quantity of 1,8-cineole and dry weight of mycelium, colony diameter.

1,8-cineole of $93.69 \%$ RA, and in poplar sawdust with of $91.25 \%$ RA. A similar performance for the production of 1,8-cineole has not been achieved by other fungi growing agro-forest residues thus far [1] [9] [22] [23]. Different carbohydrates affected the production of 1,8-cineole in fungi. Annulohypoxylon sp. FPYF3050 did not produce the 1,8-cineole when cellulose (CM and rice straw), carboxymethyl cellulose (CMC) and sucrose (CA) were used carbohydrates source (Table 1 and Table 2). Starch (PDA, MEA and OA) and lignocelluloses (poplar and pine sawdust) as carbon sources did facilitate 1,8-cineole production in Annulohypoxylon sp. (Table 1 and Table 2). However, starch, glucose, and cellobiose as a source of carbohydrates, were reported to facilitate higher concentrations of 1,8-cineole of Hypoxylon sp. CI4A [9].

Therefore, the Annulohypoxylon sp. FPYF3050 would be a feasible organism to maximize 1,8-cineole production in industry. Interestingly, 1,8-cineole was abundantly maintained in the VOCs mixture with the lignocelluloses biomass, such as raw poplar and pine residues which are most abundant supply of agricultural and forestry waster in the world. The content of 1,8-cineole in fungal VOCs was quantified with internal stand method by HS-SPEM-GC-FID [39] [40]. In this study, Annulohypoxylon sp. FPYF3050 on PDA in Petri with $9 \mathrm{~cm}$ diameter yielded 1,8-cineole with 0.764 ppmv. The alternative process for 1,8cineole in industrial scale will attenuate to dependence on Eucalyptus plants, which are raw materials for producing natural 1,8-cineole by distillation methods with best quality of $80 \%$ in fine oil [18] [41]. Fungal 1,8-cineole production is a more economically and environmentally friendly method to acquire 1,8 cineole than that of plant extraction. Also, this study has meaningful implica- 
tions that the substrate of poplar sawdust was used as medium to produce 1,8cineole of optimal yield. Moreover, the strain FPYF3050 seems to possess a stable production of 1,8-cineole with constant transfer to different media and different cultural conditions over the course of time (data not showed). Furthermore, it would be an ideal organism for studying 1,8-cineole or monoterpene metabolic pathways of fungi [40] [42]. The genome of the strain FPYF3050 has just been sequenced with the size of ca. $43 \mathrm{M}$, and twelve terpene synthases have been found in the genome (data not show). This organism could nice serve for subsequent enzyme and bioengineering analyses. Fungal monoterpenes serve important functions in economic in the ecology of fungi but little knowledge exists about their biosynthesis and biological interactions.

\section{Conclusion}

This study illustrates that the endophytic fungus FPYF3050, which was identified as an Annulohypoxylon species by phylogenetic analysis, can grow on different substrates and produce 1,8-cinole. The fungus, especially on poplar sawdust, grows quickly and produces only five VOCs. Among them, 1,8-cineole accounted for $91.25 \%$. 1,8-Cineole, an octane derivative, has been tested as a fuel additive or even as a biofuel [20] [21]. Compared with sourcing the plant as a means to acquire 1,8-cineole, FPYF3050 can not only reduce costs but also take full advantage of agro-forest residue to produce 1,8-cineole quickly. It appears that Annulohypoxylon sp. FPYF3050 has interesting potential applications in the fields of industry and biofuels since it is so capable of making 1,8-cineole from biomass residues.

\section{Acknowledgements}

This report was supported by State Forestry Administration 948 Projects grant No. 2013-4-10 and Fundamental Research Funds of CAF Grant No. CAFYBB2017MA010. The authors are also grateful to Forest Ecosystem State Field Scientific Observation Station of Jianfenglin for providing assistances for our collecting samples.

\section{References}

[1] Riyaz-Ul-Hassan, S., Strobel, G., Geary, B. and Sears, J. (2013) An Endophytic Nodulisporium sp. from Central America Producing Volatile Organic Compounds with Both Biological and Fuel Potential. Journal of Microbiology \& Biotechnology, 23, 29. https://doi.org/10.4014/jmb.1208.04062

[2] Smith, S.A., Tank, D.C., Boulanger, L.A., Bascomslack, C.A., Eisenman, K. and Kingery, D. (2007) Bioactive Endophytes Warrant Intensified Exploration and Conservation. PLoS ONE, 3, e3052. https://doi.org/10.1371/journal.pone.0003052

[3] Hibbett, D.S. and Taylor, J.W. (2013) Fungal Systematics: Is a New Age of Enlightenment at Hand? Nature Reviews Microbiology, 11, 129-133. https://doi.org/10.1038/nrmicro2963

[4] Schoch, C.L., Seifert, K.A., Huhndorf, S., Robert, V., Spouge, J.L., Levesque, C.A., Chen, W. and Consortium, F.B. (2012) Nuclear Ribosomal Internal Transcribed 
Spacer (ITS) Region as a Universal DNA Barcode Marker for Fungi. PNAS, 19, 6241-6246. https://doi.org/10.1073/pnas.1117018109

[5] Hsieh, H.M., Ju, Y.M. and Rogers, J.D. (2005) Molecular Phylogeny of Hypoxylon and Closely Related Genera. Mycologia, 97, 844.

https://doi.org/10.1080/15572536.2006.11832776

[6] Mends, M.T., Yu, E., Strobel, G.A. and Riyaz-Ul-Hassan, S. (2012) An Endophytic Nodulisporium sp. Producing Volatile Organic Compounds Having Bioactivity and Fuel Potential. Journal of Petroleum \& Environmental Biotechnology, 3, 33-47. https://doi.org/10.4172/2157-7463.1000117

[7] Strobel, G. and Daisy, B. (2004) Bioprospecting for Microbial Endophytes and Their Natural Products. Microbiology \& Molecular Biology Reviews, 67, 491-502. https://doi.org/10.1128/MMBR.67.4.491-502.2003

[8] Strobel, G.A., Knighton, B., Kluck, K. and Ren, Y.H. (2008) The Production of Myco-Diesel Hydrocarbons and Their Derivatives by the Endophytic Fungus Gliocladium Roseum (NRRL 50072). Microbiology, 154, 3319-3328.

https://doi.org/10.1099/mic.0.2008/022186-0

[9] Tomsheck, A.R., Strobel, G.A., Booth, E., Geary, B., Spakowicz, D. and Knighton, B. (2010) Hypoxylon sp., an Endophyte of Persea indica, Producing 1,8-Cineole and Other Bioactive Volatiles with Fuel Potential. Microbial Ecology, 60, 903-914. https://doi.org/10.1007/s00248-010-9759-6

[10] Ulhassan, S.R., Strobel, G.A., Booth, E., Knighton, B., Floerchinger, C. and Sears, J. (2012) Modulation of Volatile Organic Compound Formation in the MycodieselProducing Endophyte Hypoxylon sp. CI-4. Microbiology, 158, 465-473. https://doi.org/10.1099/mic.0.054643-0

[11] Booth, E., Strobel, G., Knighton, B., Sears, J., Geary, B. and Avci, R. (2011) A Rapid Column Technique for Trapping and Collecting of Volatile Fungal Hydrocarbons and Hydrocarbon Derivatives. Biotechnology Letters, 33, 1963-1972. https://doi.org/10.1007/s10529-011-0660-2

[12] Mallette, N.D., Knighton, W.B., Strobel, G.A., Carlson, R.P. and Peyton, B.M. (2012) Resolution of Volatile Fuel Compound Profiles from Ascocoryne sarcoides. A Comparison by Proton Transfer Reaction-Mass Spectrometry and Solid Phase Microextraction Gas Chromatography-Mass Spectrometry. AMB Express, 2, 23. https://doi.org/10.1186/2191-0855-2-23

[13] Strobel, G.A. (2014). Methods of Discovery and Techniques to Study Endophytic Fungi Producing Fuel-Related Hydrocarbons. Natural Product Reports, 31, 259 272. https://doi.org/10.1039/c3np70129h

[14] Stoppacher, N., Kluger, B., Zeilinger, S., Krska, R. and Schuhmacher, R. (2010). Identification and Profiling of Volatile Metabolites of the Biocontrol Fungus Trichoderma atroviride by HS-SPME-GC-MS. Journal of Microbiological Methods, 81, 187-193. https://doi.org/10.1016/j.mimet.2010.03.011

[15] Joseph, B. and Priya, R.M. (2011) Bioactive Compounds from Endophytes and Their Potential in Pharmaceutical Effect: A Review. American Journal of Biochemistry and Molecular Biology, 1, 291-309. https://doi.org/10.3923/ajbmb.2011.291.309

[16] Strobel, G. (2006) Muscodor albus and Its Biological Promise. Journal of Industrial Microbiology \& Biotechnology, 33, 514. https://doi.org/10.1007/s10295-006-0090-7

[17] Strobel, G. (2014) The Story of Mycodiesel. Current Opinion in Microbiology, 19, 52. https://doi.org/10.1016/j.mib.2014.06.003

[18] Babu, G.D.K. and Singh, B. (2009) Simulation of Eucalyptus cinerea Oil Distillation: a Study on Optimization of 1,8-Cineole Production. Biochemical Engineering Jour- 
nal, 44, 226-231. https://doi.org/10.1016/j.bej.2008.12.012

[19] Yani, S., Gao, X., Grayling, P. and Wu, H. (2014) Steam Distillation of Mallee Leaf: Extraction of 1,8-Cineole and Changes in the Fuel Properties of Spent Biomass. Fuel, 133, 341-349. https://doi.org/10.1016/j.fuel.2014.05.030

[20] Verma, P., Sharma, M.P. and Dwivedi, G. (2015) Potential Use of Eucalyptus Biodiesel in Compressed Ignition Engine. Egyptian Journal of Petroleum, 25, 91-95. https://doi.org/10.1016/j.ejpe.2015.03.008

[21] Yáñezs, M., Rojas, J., Castro, J. and Ragauskas, A. (2013) Fuel Ethanol Production from Eucalyptus globulus Wood by Autocatalized Organosolv Pretreatment Ethanol-Water and SSF. Journal of Chemical Technology \& Biotechnology, 88, 39-48. https://doi.org/10.1002/jctb.3895

[22] Strobel, G., Booth, E., Schaible, G., Mends, M.T., Sears, J. and Geary, B. (2013) The Paleobiosphere: A Novel Device for the In Vivo Testing of Hydrocarbon ProducingUtilizing Microorganisms. Biotechnology Letters, 35, 539. https://doi.org/10.1007/s10529-012-1123-0

[23] Zhang, X.H. (2009) Volatile Oil Constituents of Two Acremonium Endophyte Isolates from Aquilaria sinensis. Microbiology, 36, 37-40.

[24] Ezra, D., Jasper, J., Rogers, T., Knighton, B., Grimsrud, E. and Strobel, G. (2004) Proton Transfer Reaction-Mass Spectrometry as a Technique to Measure Volatile Emissions of Muscodor albus. Plant Science, 166, 1471-1477. https://doi.org/10.1016/j.plantsci.2004.01.022

[25] Arnold, A.E. and Lutzoni, F. (2007) Diversity and Host Range of Foliar Fungal Endophytes: Are Tropical Leaves Biodiversity Hotspots? Ecology, 88, 541. https://doi.org/10.1890/05-1459

[26] Jasalavich, C.A., Ostrofsky, A. and Jellison, J. (2000) Detection and Identification of Decay Fungi in Spruce Wood by Restriction Fragment Length Polymorphism Analysis of Amplified Genes Encoding rRNA. Applied \& Environmental Microbiology, 66, 4725-4734. https://doi.org/10.1128/AEM.66.11.4725-4734.2000

[27] White, T.J., Bruns, T.D., Lee, S.B., Taylor, J.W., Innis, M.A., Gelfand, D.H. and Sninsky, J.J. (1990) Amplification and Direct Sequencing of Fungal Ribosomal RNA Genes for Phylogenetics. PCR Protocols: A Guide to Methods and Applications, 315-322. https://doi.org/10.1016/b978-0-12-372180-8.50042-1

[28] Rehner, S.A. and Buckley, E. (2005) A Beauveria Phylogeny Inferred from Nuclear ITS and EF1- $\alpha$ Sequences: Evidence for Cryptic Diversification and Links to Cordyceps Teleomorphs. Mycologia, 97, 84.

[29] O’Donnell, K. and Cigelnik, E. (1997) Two Divergent Intragenomic rDNA ITS2 Types within a Monophyletic Lineage of the Fungus Fusarium Are Nonorthologous. Molecular Phylogenetics and Evolution, 7, 103.

https://doi.org/10.1006/mpev.1996.0376

[30] Glass, N.L. and Donaldson, G.C. (1995) Development of Primer Sets Designed for Use with the PCR to amplify Conserved Genes from Filamentous Ascomycetes. Applied and Environmental Microbiology, 61, 1323-1330.

[31] Ronquist, F. and Huelsenbeck, J.P. (2003) MrBayes 3: Bayesian Phylogenetic Inference under Mixed Models. Bioinformatics, 19, 1572-1574.

https://doi.org/10.1093/bioinformatics/btg180

[32] Katoh K. and Toh, H. (2008) Recent Developments in the MAFFT Multiple Sequence Alignment Program. Briefings in Bioinformatics, 9, 286. https://doi.org/10.1093/bib/bbn013

[33] Müller, K.F. and Stöver, B.C. (2010) TreeGraph 2: Combining and Visualizing Evi- 
dence from Different Phylogenetic Analyses. BMC Bioinformatics, 11, 7. https://doi.org/10.1186/1471-2105-11-7

[34] Smith, J.M. (1962) Disruptive Selection, Polymorphism and Sympatric Speciation. Nature, 195, 60-62. https://doi.org/10.1038/195060a0

[35] Borjesson, T.S., Stollman, U.M. and Schnurer, J.L. (1993) Off-Odorous Compounds Produced by Molds on Oatmeal Agar: Identification and Relation to Other Growth Characteristics. Journal of Agricultural and Food Chemistry, 41, 445-448. https://doi.org/10.1021/jf00035a053

[36] Andrews, S. (1992) Differentiation of Alternaria Species Isolated from Cereals on Dichloran Malt Extract Agar.

[37] Mallette, N., Pankratz, E.M., Parker, A.E., Strobel, G.A., Busse, S.C., Carlson, R.P. and Peyton, B.M. (2014) Evaluation of Cellulose as a Substrate for Hydrocarbon Fuel Production by (NRRL 50072). Journal of Sustainable Bioenergy Systems, 4, 33 49. https://doi.org/10.4236/jsbs.2014.41004

[38] Peláez, F., Platas, G. and Sánchez-Ballesteros, J. (2008) Molecular Phylogenetic Studies within the Xylariaceae Based on Ribosomal DNA Sequences. Fungal Diversity, 31.

[39] Kocak, B. and Darici, C. (2016) Priming Effects of Leaves of Laurus nobilis L. and 1,8-Cineole on Carbon Mineralization. Chilean Journal of Agricultural Research, 76, 100-104. https://doi.org/10.4067/S0718-58392016000100014

[40] Shaw, J.J., Berbasova, T., Sasaki, T., Jeffersongeorge, K., Dunican, B.F., Portero, C.E., Narváeztrujillo, A. and Strobel, S.A. (2015) Identification of a Fungal 1,8Cineole Synthase from Hypoxylon sp. with Specificity Determinants in Common with the Plant Synthases. Journal of Biological Chemistry, 290, 8511-8526. https://doi.org/10.1074/jbc.M114.636159

[41] Zrira, S., Bessiere, J.M., Menut, C., Elamrani, A. and Benjilali, B. (2004) Chemical Composition of the Essential Oil of Nine Eucalyptus Species Growing in Morocco. Flavour and Fragrance Journal, 19, 172-175. https://doi.org/10.1002/ffj.1289

[42] Wu, W., Tran, W., Taatjes, C.A., Alonso-Gutierrez, J., Lee, T.S. and Gladden, J.M. (2016) Rapid Discovery and Functional Characterization of Terpene Synthases from Four Endophytic Xylariaceae. PLoS ONE, 11, e0146983.

https://doi.org/10.1371/journal.pone.0146983 
Supplementary Table S1. Primer sequences for PCR.

\begin{tabular}{|c|c|c|}
\hline Locus & Primer & Oligo nucleotides (5'-3') \\
\hline \multirow{2}{*}{ ITS } & ITS1 & TCC GTA GGT GAA CCT GCG G \\
\hline & ITS4 & TCC TCC GCT TAT TGA TAT GC \\
\hline \multirow{2}{*}{ ACT } & ACT512F & ATG TGC AAG GCC GGT TTC G \\
\hline & ACT783R & TAC GAG TCC TTC TGG CCC AT \\
\hline \multirow{2}{*}{$\beta$-tubulin } & BT2A & $\begin{array}{c}\text { GGT AAC CAA ATC GGT GCT } \\
\text { GCT TTC }\end{array}$ \\
\hline & BT2B & $\begin{array}{c}\text { ACC CTC AGT GTA GTG ACC } \\
\text { CTT GGC }\end{array}$ \\
\hline \multirow{2}{*}{ TEF1 $\alpha$} & EF1-983F & $\begin{array}{c}\text { GCY CCY GGH CAY CGT GAY } \\
\text { TTY AT }\end{array}$ \\
\hline & EF1-2218R & $\begin{array}{c}\text { ATG ACA CCR ACR GCR ACR } \\
\text { GTY TG }\end{array}$ \\
\hline
\end{tabular}

Supplementary Table S2. Data of colony diameter, dry weight of mycelium and quantity of 1,8-cineole in different culture time (The diameter of initial inoculums plug is $5 \mathrm{~mm}$. The strain FPYF3050 was in $25^{\circ} \mathrm{C}$ constant temperature for 1 to 6 days).

\begin{tabular}{cccc}
\hline $\begin{array}{c}\text { Culture time } \\
(\text { day })\end{array}$ & $\begin{array}{c}\text { Colony diameter } \\
(\mathrm{mm})\end{array}$ & $\begin{array}{c}\text { Dry weight of mycelium } \\
(\mathrm{mg})\end{array}$ & $\begin{array}{c}\text { Quantity of 1,8-cineole } \\
(\mathrm{ppmv})\end{array}$ \\
\hline 1 & $7.27 \pm 0.28$ & $0.13 \pm 0.06$ & $0.012 \pm 0.002$ \\
2 & $23.73 \pm 0.55$ & $0.27 \pm 0.16$ & $0.017 \pm 0.003$ \\
3 & $34.00 \pm 0.62$ & $1.08 \pm 0.25$ & $0.063 \pm 0.005$ \\
4 & $54.13 \pm 0.38$ & $3.40 \pm 0.29$ & $0.213 \pm 0.017$ \\
5 & $72.27 \pm 1.22$ & $6.50 \pm 0.17$ & $0.492 \pm 0.037$ \\
6 & $82.93 \pm 0.37$ & $9.97 \pm 0.15$ & $0.764 \pm 0.044$
\end{tabular}




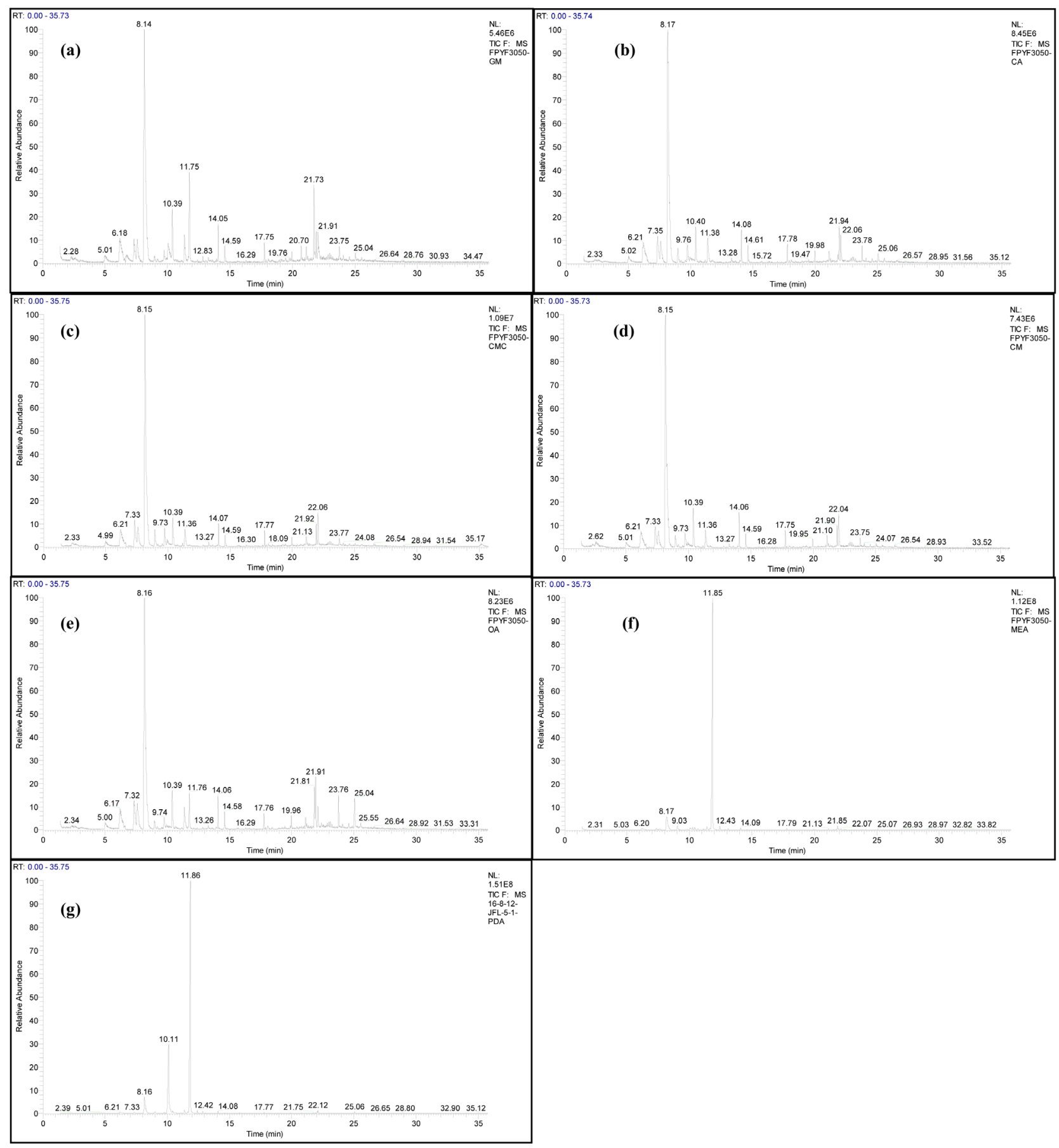

Supplementary Figure S1. GC/MS figures of the volatile compounds produced by FPYF3050 on 7 medium using a SPME fiber. A is GM media. $\mathrm{B}$ is CA media. $\mathrm{C}$ is CMC media. $\mathrm{D}$ is $\mathrm{CM}$ media. $\mathrm{E}$ is OA media. $\mathrm{F}$ is MEA media. $\mathrm{G}$ is PDA media. 


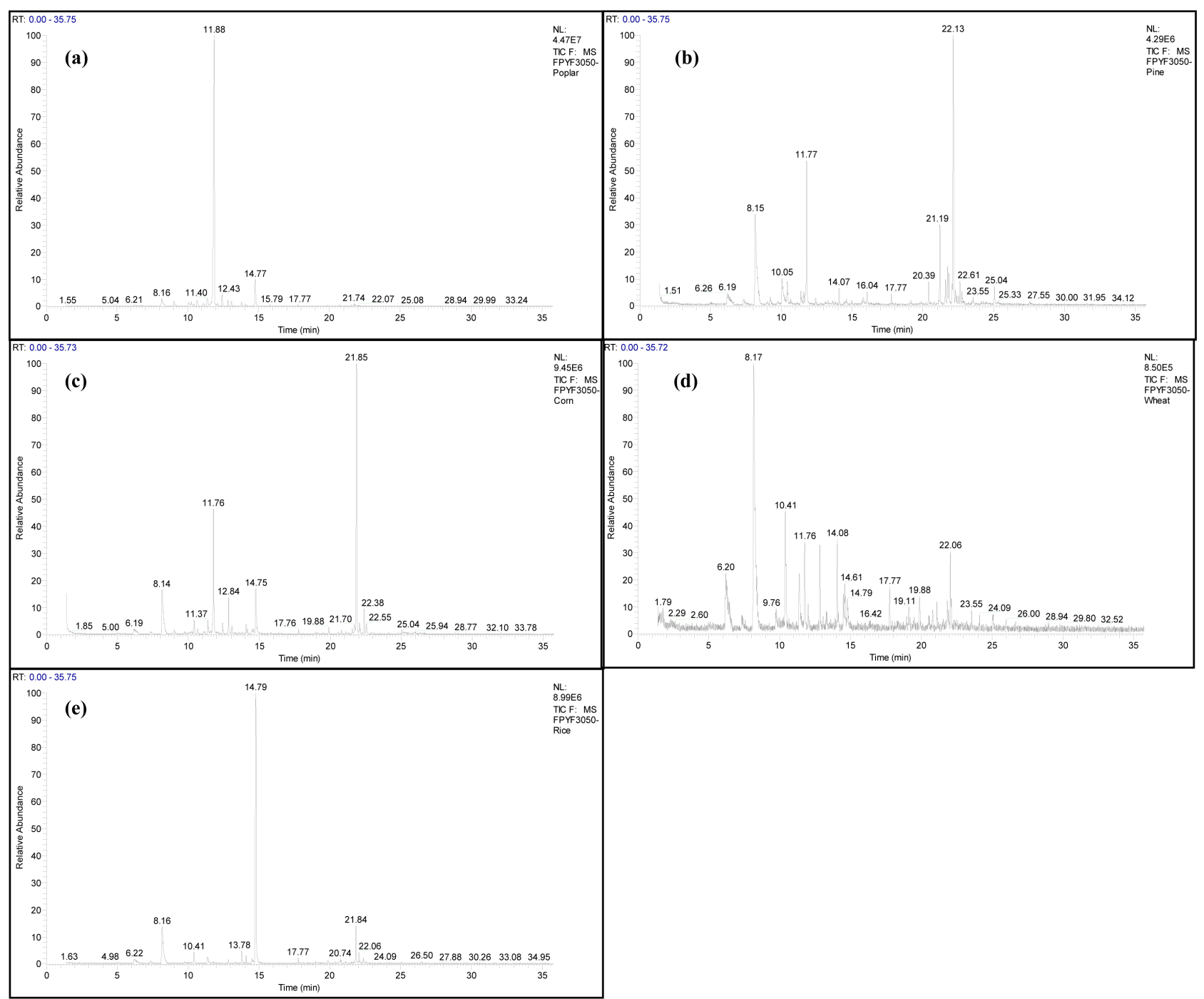

Supplementary Figure S2. GC/MS figures of the volatile compounds produced by FPYF3050 on 5 agro-forest residue medium using a SPME fiber. A is Poplar media. B is Pine media. C is Corn media. D is Wheat media. E is Rice media.

\section{Scientific Research Publishing}

Submit or recommend next manuscript to SCIRP and we will provide best service for you:

Accepting pre-submission inquiries through Email, Facebook, LinkedIn, Twitter, etc. A wide selection of journals (inclusive of 9 subjects, more than 200 journals)

Providing 24-hour high-quality service

User-friendly online submission system

Fair and swift peer-review system

Efficient typesetting and proofreading procedure

Display of the result of downloads and visits, as well as the number of cited articles Maximum dissemination of your research work

Submit your manuscript at: http://papersubmission.scirp.org/

Or contact jsbs@scirp.org 